\title{
Sobre o gênero Diaspidistis (Hemiptera, Diaspididae), com a descrição de duas espécies novas
}

\author{
Vera R. S. Wolff ${ }^{1} \&$ Lucía E. Claps ${ }^{2}$ \\ 1. Fundação Estadual de Pesquisa Agropecuária, Rua Gonçalves Dias, 570, 90130-060 Porto Alegre, RS. Brasil. (vera-wolff@ fepagro.rs.gov.br) \\ 2. Instituto Superior de Entomología "Dr. Abraham Willink", Facultad de Ciencias Naturales e Instituto Miguel Lillo, Universidad \\ Nacional de Tucumán, Miguel Lillo 205, 4000 San Miguel de Tucumán, Argentina. (luciaclaps@arnet.com.ar)
}

\begin{abstract}
About Diaspidistis (Hemiptera, Diaspididae) with description of two new species. The genus Diaspidistis Hempel, 1900 was studied. Diaspidistis multilobis Hempel, 1900 and D. squamosa Hempel, 1937 were redescribed. New combinations are proposed: D. gomescostai (Lepage \& Giannotti, 1946), D. memorabilis (Ferris, 1941), D. multipunctata (Lepage \& Giannotti, 1946) and D. petasata (Ferris, 1942). Two new species are described and illustrated: Diaspidistis fonsecai sp. nov. and Diaspidistis tucumanensis sp. nov. A key to the species is presented based on adult females.
\end{abstract}

KEYWORDS. Armored scale insect, Neotropical, taxonomic revision, Diaspidistis fonsecai sp. nov., Diaspidistis tucumanensis sp. nov.

RESUMO. O gênero Diaspidistis Hempel, 1900 foi estudado. Foram redescritas Diaspidistis multilobis Hempel, 1900 e D. squamosa Hempel, 1937. Novas combinações são propostas: D. gomescostai (Lepage \& Giannotti, 1946), D. memorabilis (Ferris, 1941), D. multipunctata (Lepage \& Giannotti, 1946) e D. petasata (Ferris, 1942). São descritas e ilustradas duas espécies novas: Diaspidistis fonsecai sp. nov. e Diaspidistis tucumanensis sp. nov. Uma chave para identificação das espécies é apresentada baseada em fêmeas adultas.

PALAVRAS-ChAVE. Cochonilhas-com-escudo, Neotropical, revisão taxonômica, Diaspidistis fonsecai sp. nov., Diaspidistis tucumanensis sp. nov.

A descrição de Diaspidistis Hempel, 1900 é muito resumida. FERRIS (1937) comenta que este gênero é muito próximo de Pseudoparlatoria Cockerell, 1892, mas que necessitava de adequado reconhecimento.

As espécies de Pseudoparlatoria não apresentam glândulas periespiraculares nos espiráculos anteriores e as glândulas dorsais marginais são maiores que as glândulas dorsais submarginais (WoLFF, 2001, 2008). Na descrição de Diaspidistis multilobis Hempel, 1900 e D. squamosa Hempel, 1937 consta que há glândulas ao redor dos espiráculos anteriores (HEMPEL, 1900, 1937).

Pseudoparlatoria gomescostai Lepage \& Giannotti, 1946, P. memorabilis Ferris, 1941, P. multipunctata Lepage \& Giannotti, 1946 e $P$. petasata Ferris, 1942 apresentam glândulas ao redor dos espiráculos anteriores e as glândulas dorsais marginais e submarginais encontradas no pigídio são semelhantes quanto ao tamanho.

Este trabalho sobre o gênero Diaspidistis, faz quatro novas combinações, descreve duas novas espécies, além de fornecer informações sobre a localização do material-tipo, distribuição geográfica e plantas hospedeiras.

\section{MATERIAL E MÉTODOS}

Foram examinados espécimes-tipo e outros exemplares das seguintes Instituições: Fundación e Instituto Miguel Lillo, Universidad Nacional de Tucumán, San Miguel de Tucumán, Argentina (IMLA); Instituto de Microbiología y Zoología Agrícola, Centro Nacional de Investigaciones Agropecuaria, Instituto Nacional de
Tecnología Agropecuaria, Castelar, Buenos Aires, Argentina (IMYZA CNIA-INTA); Instituto Biológico, Secretaria da Agricultura, São Paulo, Brasil (IBSP); Museu de Zoologia, Universidade de São Paulo, São Paulo, Brasil (MZSP); The Bohart Museum of Entomology, University of California, Davis, USA (UCDC).

Os desenhos esquemáticos apresentados nas figuras foram feitos a partir da captura de imagem com câmara digital acoplada ao microscópio óptico de exemplares fixados em lâminas.

Medidas são expressas em milímetros.

Lectótipos e paralectótipos são designados.

\section{Diaspidistis Hempel, 1900}

Diaspidistis Hempel, 1900:522. Espécie-tipo, Diaspidistis multilobis, por designação original.

Descrição conforme Hempel (1900). Escudo da fêmea subcircular, exúvias sobrepostas centrais; escudo do macho branco, convexo, não carinado, mas com superfície áspera, exúvia subcentral.

Redescrição. Fêmea adulta com glândulas ao redor dos espiráculos anteriores. Glândulas dorsais tubulares pequenas nas margens do corpo, desde o cefalotórax até os primeiros segmentos abdominais. No pigídio, três pares de lóbulos, $2^{\circ}$ e $3^{\circ}$ pares bilobados podendo estar reduzidos; glândulas dorsais tubulares marginais e submarginais semelhantes quanto ao tamanho e à forma, sendo as últimas encontradas até os primeiros segmentos abdominais.

Discussão. Este gênero diferencia-se de Pseudoparlatoria por apresentar glândulas junto aos 
espiráculos anteriores e no pigídio glândulas dorsais tubulares marginais e submarginais semelhantes na forma e tamanho, além de glândulas dorsais tubulares pequenas na margem do cefalotórax e primeiros segmentos abdominais, exceto em $P$. rossetae Fonseca, 1969.

\section{Diaspidistis multilobis Hempel, 1900}

Diaspidistis multilobis Hempel, 1900:522, 523; Fernald, 1903:301 (cat.); Hempel, 1937:28; Lepage, 1938:76 (cat.); Borchsenius, 1966:159 (cat.); Silva et al., 1968:173; BEN-Dov et al., 2008 (cat.).

Diaspidistis multilobia; MacGillivray, 1921:314 (chave).

Diaspidistis multiloba; FERRIS, 1936:21; FERRIS, 1937:11, fig. 5 (descr. ㅇ).

Pseudoparlatorea multilobis; LINDINGER, 1937:194

Descrição conforme Hempel (1900). Escudo da fêmea adulta subcircular, com 2,3 de diâmetro, convexo, marrom-claro, exúvias centrais, amarelas, sobrepostas; na parte ventral com uma película fina. Escudo do macho branco, mais ou menos alongado, não carinado, superfície áspera, exúvia central, amarelo-clara, com costeleta dorsal longitudinal.

Redescrição. Fêmea adulta com o corpo cordiforme ou subcircular, membranoso, em média 0,7 de comprimento, margem anterior sempre entalhada no meio; tubérculos antenais com três a quatro setas; espiráculos anteriores com grupo de seis a oito glândulas periespiraculares. Uma série de glândulas dorsais tubulares pequenas nas margens do corpo desde o cefalotórax até os primeiros segmentos abdominais. Primeiros segmentos abdominais com dois a três lobos de cada lado com vários grupos de glândulas tubulares, menores do que as do pigídio. Glândulas tubulares dorsais marginais e submarginais do pigídio semelhante na forma e no tamanho: uma marginal no centro e cerca de oito nas laterais; cerca de 20 submarginais de cada lado. Porção ventral com quatro grupos de glândulas circungenitais: ântero-laterais de 15 a 28 e póstero-laterais de 17 a 26. Margem do pigídio com um par de lóbulos medianos com um ou dois entalhes de cada lado e ápice arredondado; um par de espinhos glandulares entre estes lóbulos; segundo e terceiro pares de lóbulos bilobados, subiguais, com margens inteiras ou finamente serrilhadas, com finas estrias longitudinais; um espinho glandular longo entre cada lóbulo. Margem pigidial anterior ao terceiro par de lóbulos com cerca de 10 processos parecidos com lóbulos, de cada lado. Abertura anal próxima ao centro do pigídio.

Nota. Macho adulto amarelo-claro, corpo alongado com 0,9 de comprimento (HEMPEL, 1900). Ilustração dos escudos de macho e fêmea adulta é apresentada em FERRIS (1937).

Material-tipo. Lectótipo $\subsetneq$ adulta, aqui designado. BRASIL, sem data, sem coletor, etiquetado como Hemichionaspis multilobis Hempel; uma lâmina com 6 espécimes, lectótipo claramente indicado na lâmina, com as seguintes medidas: 0,82 de comprimento e 0,81 de largura (MZSP sem $\mathrm{n}^{\circ}$ ). Paralectótipos: 5 $\$$ adultas na mesma lâmina do lectótipo, sem data, sem coletor, etiquetado como Hemichionaspis multilobis Hempel (MZSP sem $\mathrm{n}^{\circ}$ ); 7 q adultas, 1 lâmina, sem data, sem coletor, etiquetado como Hemichionaspis multilobis Hempel (MZSP sem ${ }^{\circ}$ ). Síntipo (não examinado): BRASIL, São Paulo: Ypiranga, 25.V.1900, ex. Myrtaceae depositado no National Museum of Natural History, Smithsonian Institution, Washington DC, USA (USNM) (Miller \& Gimpel, 2001)

Material adicional examinado. BRASIL, São Paulo: São Paulo, Morumbi, 5 O adultas, 1 lâmina, I.1961, J. P. da Fonseca col., ex. Myrtaceae (MZSP 153); idem, Muritiba, 5 adultas, 1 lâmina, XI.1961, J. P. da Fonseca col., ex. Heterothalamus brunioides (Asteraceae) (MZSP 171); São Paulo, S. Amaro, 3 adultas, 3 laminas, 02.XII.1912, H. Lepage col., ex. planta silvestre (MZSP 1518, 1519, 1528). ARGENTINA, 25 † adultas, 3 lâminas, VII.1964, G. M. Oliveira col., ex. Citrus sp. (IMYZA CNIAINTA 214)

Distribuição geográfica. Brasil (Rio de Janeiro (LePAGE, 1938); São Paulo), Argentina, localidade não especificada.

Hospedeiros. Asteraceae: Heterothalamus brunioides; Myrtaceae: Eugenia dombeyi, Psidium sp.; Rutaceae: Citrus sp.

Discussão. Segundo Hempel (1900), há 10 ou 12 glândulas ao redor dos espiráculos anteriores, número maior do que foi encontrado no material examinado; o mesmo número de glândulas circungenitais ânterolaterais, de 15 a 28 e de 18 a 27 póstero-laterais, estes últimos muito próximos do que foi encontrado no material examinado.

\section{Diaspidistis squamosa Hempel, 1937}

(Figs 1, 2)

Diaspidistis squamosa Hempel, 1937:27, 28; Lepage, 1938:76 (cat.); Borchsenius, 1966:159 (cat.); Silva et al., 1968:173; BENDov et al., 2008 (cat.).

Pseudoparlatorea squamosa; Lindinger, 1943: 219.

Descrição conforme Hempel (1937). Escudo da fêmea adulta irregular ou circular, com cerca de 2,0 de diâmetro, achatado, marrom-escuro, com uma pequena bossa central amarela-clara onde estão as exúvias e membrana ventral branca, muito fina; escudo do macho alongado, branco, superfície dorsal áspera, com 1,5 de comprimento.

Redescrição. Fêmea adulta com o corpo cordiforme, membranoso em média 0,8 de comprimento, margem anterior raras vezes um pouco entalhada no meio; tubérculos antenais com três ou quatro setas; espiráculos anteriores com um grupo de 8 a 12 glândulas periespiraculares. Uma série de glândulas dorsais curtas, tênues, nas margens do corpo desde o cefalotórax até os primeiros segmentos abdominais. Primeiros segmentos abdominais com dois a três lobos de cada lado onde se encontram na área marginal e submarginal, glândulas dorsais, menores do que as do pigídio. Glândulas tubulares dorsais marginais e submarginais do pigídio de tamanho e forma semelhantes; uma marginal central e cerca de 10 laterais; cerca de 20 submarginais, em cada lado. Porção ventral com quatro grupos de glândulas circungenitais: ântero-laterais de 11 a 19 e os pósterolaterais de 17 a 20. Margem pigidial com um par de lóbulos medianos esclerotizados, superfície com estrias longitudinais e a margem serrilhada, com um par de espinhos glandulares entre eles; segundo e terceiro pares de lóbulos bilobados, subiguais, entre cada um destes 
lóbulos há um espinho glandular. Margem lateral, além do terceiro par de lóbulos, dentada com cerca de 10 processos semelhantes a lóbulos, de cada lado. Abertura anal próxima ao centro do pigídio.

Material-tipo. Lectótipo 9 adulta, aqui designado. BRASIL, São Paulo: Araçatuba, 23.VI.1928, H. S. Hempel col., ex. Eugenia sp., uma lâmina com 2 espécimes, lectótipo claramente indicado na lâmina, com as seguintes medidas: 1,17 de comprimento e 0,98 de largura (IBSP sem ${ }^{\circ}$ ). Paralectótipo: 1 q adulta, mesma lâmina do lectótipo (IBSP sem $\mathrm{n}^{\circ}$ ); 3 q adultas, 1 lâmina, mesmos dados do lectótipo; 2 ㅇ adultas, 1 lâmina, sem dados, etiquetada como "cotipo" (MZSP sem no).

Distribuição geográfica. Brasil, São Paulo.

Hospedeiros. Myrtaceae: Eugenia sp., espécie não determinada.

Discussão. Segundo Hempel (1937), há de 8 a 16 glândulas periespiraculares, de 11 a 15 glândulas circungenitais ântero-laterais e de 16 a 23 póstero-laterais. No material examinado foram encontradas até 12 glândulas periespiraculares, até 19 glândulas circungenitais ântero-laterais e até 20 póstero-laterais. Esta espécie pode ser separada de D. multilobis pela cor do escudo da fêmea que é marrom-claro e em $D$. squamosa é marrom-escuro (HEMPEL, 1900, 1937); pela forma dos lóbulos medianos, que em $D$. multilobis tem o ápice arredondado e um ou dois entalhes de cada lado e em $D$. squamosa é serrilhada; pelo maior número de glândulas periespiraculares, menor número de glândulas circungenitais e maior número de glândulas tubulares nas margens laterais dos segmentos abdominais.

Nota. Fonseca (1969) apresentou uma figura de fêmea adulta de D. squamosa com um pronunciado entalhe no meio da margem anterior do cefalotórax, uma série de pequenas glândulas dorsais bem marcadas na margem do corpo desde o cefalotórax até os primeiros segmentos abdominais e lóbulos medianos com uma ou duas reentrâncias de cada lado e ápice arredondado. Esta figura não corresponde aos síntipos de D. squamosa observados que não apresentam estes caracteres.
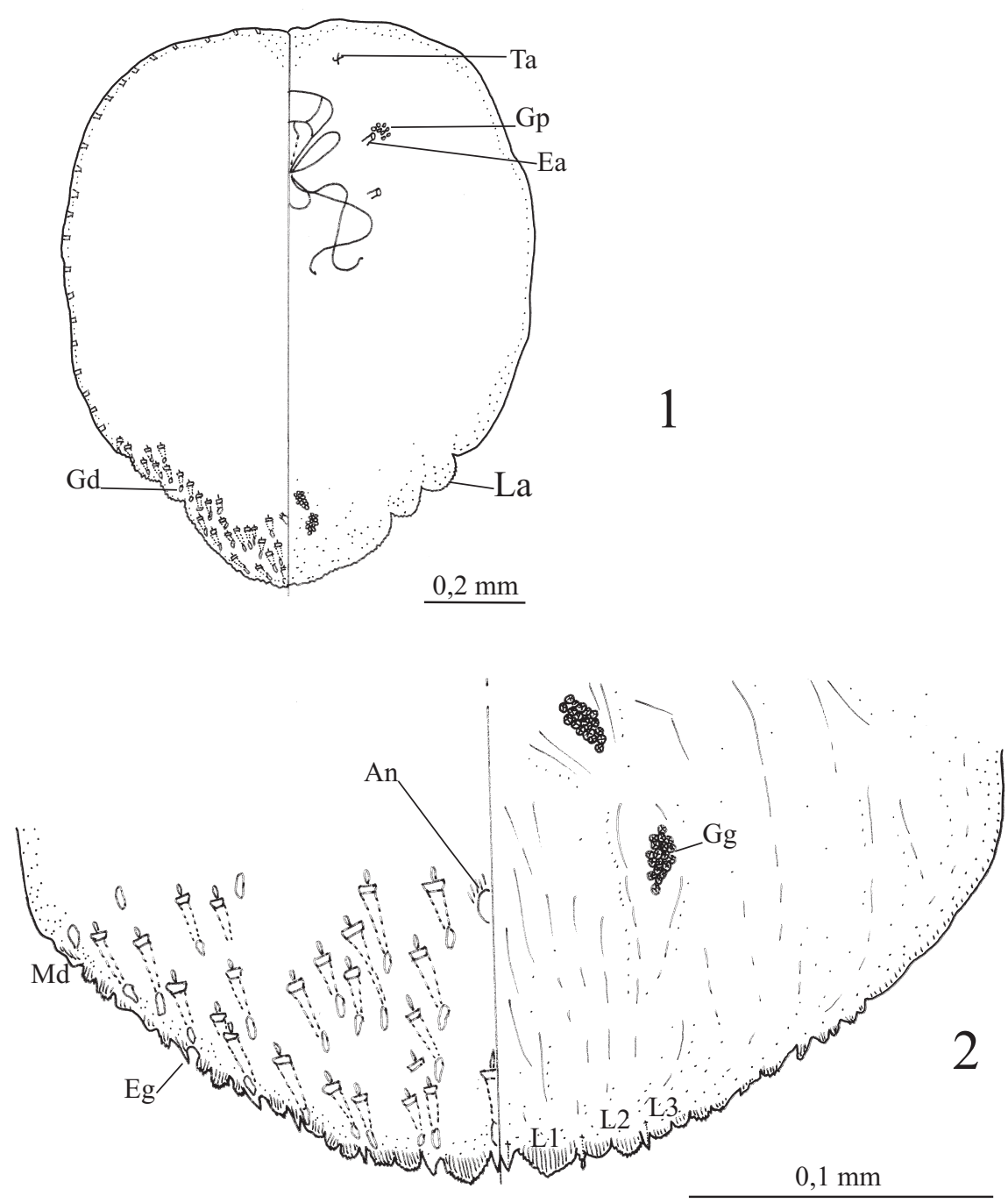

Figuras 1, 2. Desenho esquemático de Diaspidistis squamosa Hempel, 1937 (à esquerda estruturas dorsais, à direita ventrais): 1, corpo inteiro da fêmea adulta; 2, pigídio (An, ânus; Ea, espiráculo anterior; Eg, espinho glandular; Gd, glândula dorsal; Gg, glândulas circungenitais; Gp, glândulas periespiraculares; La, lobo abdominal; L1, lóbulo mediano; L2, segundo lóbulo; L3, terceiro lóbulo; Md, margem dentada; Ta, tubérculo antenal). 


\section{Diaspidistis memorabilis (Ferris, 1941) comb. nov.}

Pseudoparlatoria memorabilis FerRIs, 1941:SIII-318 (fig. sem $\mathrm{n}^{\circ}$ ); Ferris, 1942:SIV-445:62; Borchsenius, 1966:163; Ben-Dov et al., 2008.

Descrição segundo FERRIs (1941). Escudo da fêmea branco, forma irregular devido à pilosidade do hospedeiro, exúvias excêntricas; escudo do macho oval, exúvia central.

Redescrição. Fêmea adulta com o corpo subcircular, membranoso, em média 0,6 de comprimento, margem anterior lisa, tubérculos antenais com quatro setas, espiráculos anteriores com até quatro glândulas. Com mais de uma série de glândulas dorsais curtas nas margens do corpo desde o cefalotórax até os primeiros segmentos abdominais; sem lobos abdominais pré-pigidiais. Pigídio com glândulas tubulares dorsais marginais e submarginais de tamanho e forma semelhantes; uma marginal central e cerca de nove laterais; submarginais irregularmente distribuídas por todo o pigídio até os primeiros segmentos abdominais. Porção ventral do pigídio com quarto ou cinco grupos de glândulas circungenitais: medianas quando presentes até três, ântero-laterais de 6-13, póstero-laterais de 4-11. Margem do pigídio com um par de lóbulos medianos de margens serrilhadas com uma barra transversal, na base, fortemente esclerotizada e um prolongamento esclerotizado até quase a altura do ânus, um par de espinhos glandulares longos entre estes lóbulos. Segundo e terceiro pares de lóbulos pequenos, bilobados, lisos e com pouca esclerotização, entre cada um destes lóbulos há um espinho glandular longo. Margem anterior aos lóbulos pigidiais lisa apenas com espinhos glandulares.

Nota. Ilustração encontra-se em FeRRIS (1941), como P. memorabilis.

Material-tipo. Lectótipo $\subsetneq$ adulta, aqui designado. PANAMÁ, Chiriqui: Dolega, 1938, G. F. Ferris col., ex. Eugenia sp., 1 lâmina, lectótipo 0,55 de comprimento e 0,44 de largura (UCDC 64). Paralectótipos 6 ? adultas, em 3 lâminas, mesmos dados que o lectótipo (UCDC sem n ${ }^{\circ}$ ); 10 ? adultas, em 4 lâminas, mesmos dados (UCDC 169); 8 + adultas, 3 lâminas, mesmos dados (UCDC 215).

Distribuição geográfica. Panamá.

Hospedeiros. Myrtaceae: Eugenia sp.

Discussão. Diaspidistis memorabilis é semelhante à D. squamosa e D. multipunctata (Lepage \& Giannotti, 1946) comb. nov., pela presença de uma barra fortemente esclerotizada na base dos lóbulos medianos, porém estas diferem pelos lóbulos medianos mais largos e presença de lobos abdominais pré-pigidiais. Esta espécie apresenta glândulas ao redor dos espiráculos anteriores e glândulas tubulares dorsais marginais e submarginais de tamanho e forma semelhantes, características de Diaspidistis.

\section{Diaspidistis petasata (Ferris, 1942) comb. nov.}

Pseudoparlatoria petasata FerRIs, 1942:SIV-419 (fig. sem nº) SIV-446:62; Borchsenius, 1966:164; Ben-Dov et al., 2008 (cat.).

Descrição segundo FERRIS (1942). Escudo da fêmea circular. A segunda exúvia apresenta uma fenda.
Redescrição. Fêmea adulta de forma indeterminada, provavelmente oval, membranosa, com menos de 1,0 de comprimento, com uma série de pequenas glândulas desde o cefalotórax até os primeiros segmentos abdominais (FERris, 1942). Pigídio com glândulas tubulares dorsais marginais e submarginais de tamanho e forma semelhantes; uma marginal central e cerca de sete de cada lado; submarginais irregularmente distribuídas por todo o pigídio. Porção ventral com quatro grupos de glândulas circungenitais: ântero-laterais 15; póstero-laterais 17. Margem pigidial com um par de lóbulos medianos grandes, espatulados, com uma reentrância de cada lado e ápice arredondado, com um par de espinhos glandulares entre os lóbulos; segundo e terceiro pares de lóbulos bilobados, com um espinho glandular entre cada lóbulo. Margem anterior ao terceiro par de lóbulos sem estruturas especiais. Abertura anal grande mais próxima da base do pigídio.

Material-tipo. Holótipo + adulta. Uma lâmina com 1 † adulta e 4 exúvias do primeiro instar. MÉXICO, Veracruz: Santa Lucrecia, 1926, G. F. Ferris det., planta não determinada (UCDC 372).

Distribuição geográfica. México, Veracruz.

Hospedeiro. Planta indeterminada.

Discussão. FERRIS (1942) sugere que esta espécie poderia estar relacionada com Diaspidistis, especialmente pelas pequenas glândulas dorsais encontradas na margem do cefalotórax até os primeiros segmentos abdominais. Esta espécie é transferida para Diaspidistis porque, além destas glândulas dorsais citadas por FerRIS (1942), apresenta também glândulas tubulares dorsais marginais e submarginais de tamanho e forma semelhantes.

\section{Diaspidistis gomescostai (Lepage \& Giannotti, 1946) comb.nov.}

Pseudoparlatoria gomescostai LePAgE \& GiannotTI, 1946:41, 42 (figs 9-12); Costa \& RedAelli, 1949:72-74; BoRCHSENIUS, 1966:63; Silva et al.,1968:180; Corseuil \& Silva, 1971:111; Vernalha, 1953:193; Williams, 1985:255; Claps et al., 2001:251; Miller \& GiMPEL, M. E. 2006.

Descrição segundo LePAGE \& GiannotTi (1946). Escudo da fêmea circular, de cor escura, exúvias centrais amarelo-claras; escudo do macho alongado, menor que o da fêmea.

Redescrição. Fêmea adulta com corpo subcircular, membranoso em média 0,7 de comprimento, sem entalhe na margem anterior; tubérculos antenais com duas a quatro setas; espiráculos anteriores com um grupo de cinco a 20 glândulas periespiraculares. Mais de uma série de glândulas dorsais curtas nas margens do corpo desde o cefalotórax até os primeiros segmentos abdominais. Primeiros segmentos abdominais com dois a três lobos marginais com vários grupos de glândulas dorsais. Pigídio com glândulas tubulares dorsais marginais e submarginais de tamanho e forma semelhantes; uma marginal central e cerca de sete laterais; submarginais irregularmente distribuídos por todo o pigídio, sendo que depois deste vão diminuindo de tamanho até chegarem à altura do espiráculo posterior. Porção ventral com quatro grupos de glândulas circungenitais: ântero-laterais de 6 
a 20 e póstero-laterais em média de 13 a 29. Margem pigidial com um par de lóbulos medianos espatulados, com um pequeno entalhe de cada lado, com um par de espinhos glandulares entre eles; segundo e terceiro pares de lóbulos menores, bilobados, com um espinho glandular entre cada um deles. Margem anterior ao terceiro par de lóbulos com pequenos processos semelhantes a lóbulos. Abertura anal pequena, aproximadamente no centro do pigídio.

Nota. Ilustração em LePAGE \& GianNOTTI (1946).

Síntipos fêmeas. BRASIL, São Paulo. Espécimes depositados no (IBSP) e (MZSP) não foram localizados.

Material adicional examinado. BRASIL, 18 adultas, 4 lâminas, sem dados (MZSP sem $\mathrm{n}^{\circ}$ ).

Distribuição geográfica. Brasil, Rio Grande do Sul (Lepage \& GiannotTi, 1946; Silva et al., 1968).

Hospedeiro. Myrtaceae: Eugenia pungens (LEPAGE \& GianNotTI, 1946; SiLva et al.,1968).

Discussão. Esta espécie é semelhante à $D$. multilobis pela forma dos lóbulos medianos, difere por não apresentar um entalhe na margem anterior. É transferida para este gênero porque apresenta glândulas junto aos espiráculos anteriores e as glândulas dorsais marginais e submarginais possuem forma e tamanho semelhantes.

\section{Diaspidistis multipunctata (Lepage \& Giannotti, 1946) comb.nov.}

Pseudoparlatoria multipunctata LePage \& Giannotti, 1946:39-41 (figs 5-8); Borchsenius, 1966:163; Claps et al., 2001: 251; BenDov et al., 2008 (cat.).

Descrição segundo LePage \& GiannotTi (1946). Escudo da fêmea arredondado, amarelo-claro, exúvias subcentrais.

Fêmea adulta com corpo oval, membranoso, em média 0,7 de comprimento, margem anterior lisa tubérculos antenais com três a quatro setas; espiráculos anteriores com três a sete glândulas periespiraculares. Mais de uma série de glândulas dorsais curtas nas margens do corpo desde o cefalotórax até os primeiros segmentos abdominais; lóbulos abdominais pré-pigidiais pouco desenvolvidos. Pigídio com glândulas tubulares dorsais marginais e submarginais de tamanho e forma semelhantes; uma marginal central e cerca de sete laterais; submarginais irregularmente distribuídas por todo o pigídio, sendo que depois deste vão diminuindo de tamanho até chegarem à altura do espiráculo posterior. Porção ventral com quatro ou cinco grupos de glândulas circungenitais: medianas quando presentes até seis; ântero-laterais de 12 a 26; póstero-laterais de 11 a 19 . Margem pigidial com um par de lóbulos medianos grandes, triangulares com a base fortemente esclerotizada e as margens laterais serrilhadas, com um par de espinhos glandulares entre eles; segundo e terceiro pares de lóbulos bilobados, com um espinho glandular entre cada um deles. Margem anterior ao terceiro par de lóbulos sem estruturas semelhantes a lóbulos. Abertura anal grande no centro do pigídio.
Nota. Ilustração em LePage \& Giannotti (1946), como $P$. multipunctata.

Material-tipo. Lectótipo $\odot$ adulta, aqui designado. BRASIL, São Paulo: Campos do Jordão, 4-1945 [sic], F. de Paula Mello col., ex. planta silvestre; uma lâmina com 2 espécimes, lectótipo claramente indicado na lâmina, com as seguintes medidas: 0,65 de comprimento e 0,58 de largura (IBSP sem $\mathrm{n}^{\circ}$ ). Paralectótipo: 1 \% adulta, mesma lâmina do lectótipo (IBSP sem n ${ }^{\circ}$ ).

Material adicional examinado. BRASIL, São Paulo: Ipiranga, 7 ㅇ adultas, 1 lâmina, 11.X.1959, J. P. da Fonseca col., ex. planta indeterminada (MZSP 119); 11 † adultas, 5 lâminas, sem dados coleta (MZSP sem $\mathrm{n}^{\circ}$ ).

Distribuição geográfica. Brasil, São Paulo.

Hospedeiro. Espécie não identificada.

Discussão. Semelhante à $D$. squamosa pela forma dos lóbulos medianos e pela esclerotização na base destes, difere pelo número de glândulas periespiraculares e margem anterior ao terceiro par de lóbulos sem apresentar processos semelhantes a lóbulos.

\section{Diaspidistis fonsecai sp. nov.} (Figs 3, 4)

Diaspidistis squamosa; FonseCA, 1969:30, 31, fig. 12 (identificação errônea).

Diagnose. As fêmeas adultas de Diaspidistis fonsecai sp. nov. diferem das demais espécies do gênero, exceto de $D$. multilobis, por apresentar pronunciado entalhe no meio da margem anterior (as fêmeas $D$. multilobis também apresentam um entalhe na margem anterior, porém menos pronunciado) e por apresentar uma série de pequenas glândulas dorsais bem marcadas.

Descrição. Fêmea adulta com o corpo cordiforme, membranoso, em média 0,7 de comprimento, margem anterior com um pronunciado entalhe no meio, tubérculos antenais com duas setas; espiráculos anteriores com grupo de 8-20 glândulas. Margem do cefalotórax até os primeiros segmentos abdominais com uma série simples de pequenas glândulas dorsais bem marcadas. Primeiros segmentos abdominais com dois ou três lobos com várias glândulas dorsais menores do que as do pigídio. Pigídio com glândulas dorsais marginais e submarginais de tamanho e forma semelhantes. Porção ventral com quatro grupos de glândulas circungenitais: ântero-laterais de 1726 glândulas, póstero-laterais de 12-19 glândulas. Margem do pigídio com um par de lóbulos medianos com uma ou duas reentrâncias de cada lado e ápice arredondado, com um par de espinhos glandulares entre eles. Segundo e terceiro pares de lóbulos pequenos, bilobados, lisos e com pouca esclerotização, entre cada um destes lóbulos há um espinho glandular que não ultrapassa o comprimento dos lóbulos. Nas margens anteriores ao terceiro par de lóbulos há cerca de 10 processos semelhantes a lóbulos e entre cada um deles há um pequeno espinho glandular.

Material-tipo. Holótipo + , BRASIL, São Paulo: Morumbi, VII-1963, J. P. da Fonseca col., ex. planta silvestre, uma lâmina como Diaspidistis squamosa com 16 9 adultas, holótipo claramente indicado na lâmina, com as seguintes medidas: 0,87 de comprimento e 0,90 de largura (MZSP 195). Parátipos: 15 \& adultas, mesma lâmina do holótipo; $20,17,14,12,10,4,4$ e 3 q adultas, em 8 
lâminas, com os mesmos dados que o holótipo; 9 adultas, 1 lâmina, sem data, sem coletor, como Pseudoparlatoria rossettae, etiquetado como "cotypus" (IBSP 857); 12 † adultas, 1 lâmina, sem data, sem coletor, como Diaspidistis squamosa, etiquetado como "cotypus" (MZSP sem no); 16, 6 e 5 ㅇ adultas em 3 lâminas, sem data, sem coletor, como Diaspidistis squamosa (MZSP sem $\left.\mathrm{n}^{\mathrm{o}}\right)$.

Material adicional examinado. ARGENTINA, 5 adultas, 1 lâmina, VII.1964, G. M. Oliveira col., ex. Citrus sp. (IMYZA CNIAINTA 214).
Discussão. A figura apresentada por FonsECA (1969) para D. squamosa apresenta os caracteres microscópicos de Diaspidistis fonsecai sp. nov. As fêmeas do material examinado da Argentina apresentam o corpo mais esclerotizado e na margem anterior ao terceiro lóbulo, até os primeiros segmentos abdominais em torno de 14 espinhos glandulares curtos.

Etimologia. O nome específico é em homenagem ao pesquisador José Pinto da Fonseca.
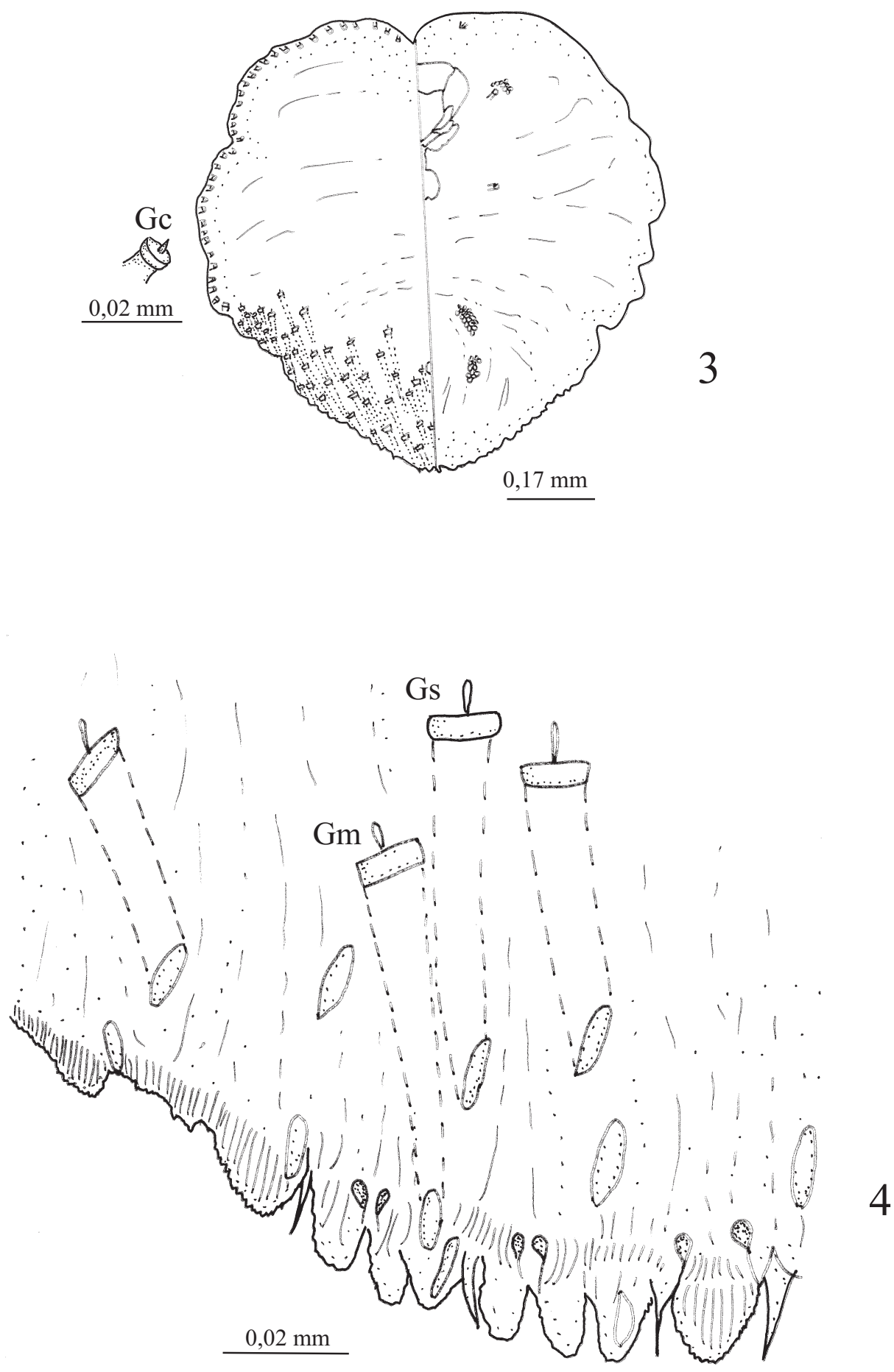

Figuras 3, 4. Desenho esquemático de Diaspidistis fonsecai sp. nov.: 3, corpo inteiro da fêmea adulta (à esquerda estruturas dorsais, à direita ventrais); 4, margem pigidial (Gc, glândula dorsal curta; Gm, glândula tubular marginal; Gs, glândula tubular submarginal). 


\section{Diaspidistis tucumanensis sp. nov.}

(Figs 5, 6)

Diagnose. As fêmeas adultas de Diaspidistis tucumanensis sp. nov. diferem das demais espécies deste gênero por apresentarem todo o corpo fortemente esclerotizado, piriforme e maior quantidade de espinhos curtos na margem anterior ao terceiro lóbulo pigidial.

Descrição. Fêmea adulta com o corpo piriforme, fortemente esclerotizado, em média 0,6 de comprimento, margem anterior sem entalhe, raro com pequeno entalhe no meio; tubérculos antenais com três ou quatro setas; espiráculos anteriores com quatro ou cinco glândulas periespiraculares. Com mais de uma série de glândulas dorsais curtas nas margens do corpo desde o cefalotórax até os primeiros segmentos abdominais; sem lobos abdominais pré-pigidiais. Pigídio com glândulas tubulares dorsais marginais e submarginais semelhantes na forma e no tamanho: uma marginal no centro e cerca de oito nas laterais. Porção ventral com quatro ou cinco grupos de glândulas circungenitais: mediana, quando presente, apenas uma glândula; ântero-laterais de 11 a 16 e póstero- laterais de 14 a 17. Margem do pigídio com um par de lóbulos medianos fortemente esclerotizados na base, mais largos do que longos, com as margens laterais serrilhadas, com um par de espinhos glandulares entre eles, mais longos que estes. Segundo e terceiro pares de lóbulos pequenos, bilobados, lisos, entre cada um destes lóbulos há um espinho glandular que ultrapassa o comprimento dos lóbulos e outro espinho glandular longo anterior ao terceiro par de lóbulos. Na margem anterior ao terceiro lóbulo, até os primeiros segmentos abdominais há cerca de 14 espinhos curtos. Abertura anal próxima ao centro do pigídio.

Material-tipo. Holótipo $\subsetneq$ adulta, ARGENTINA, Tucumán: San Pedro de Colalao, VIII.1996, L. Claps col., ex. Eugenia mato (Myrtaceae), uma lâmina com 4 espécimes, holótipo claramente indicado na lâmina, com as seguintes medidas: 0,92 de comprimento e 0,63 de largura (IMLA C. 96.96). Parátipos: 3 q adultas, mesma lâmina do holótipo; 4 \& adultas, 1 lâmina, mesma data (IMLA sem no).

Discussão. Esta espécie é semelhante à $D$. memorabilis, sem lobos abdominais pré-pigidiais e forma dos lóbulos medianos com uma barra transversal
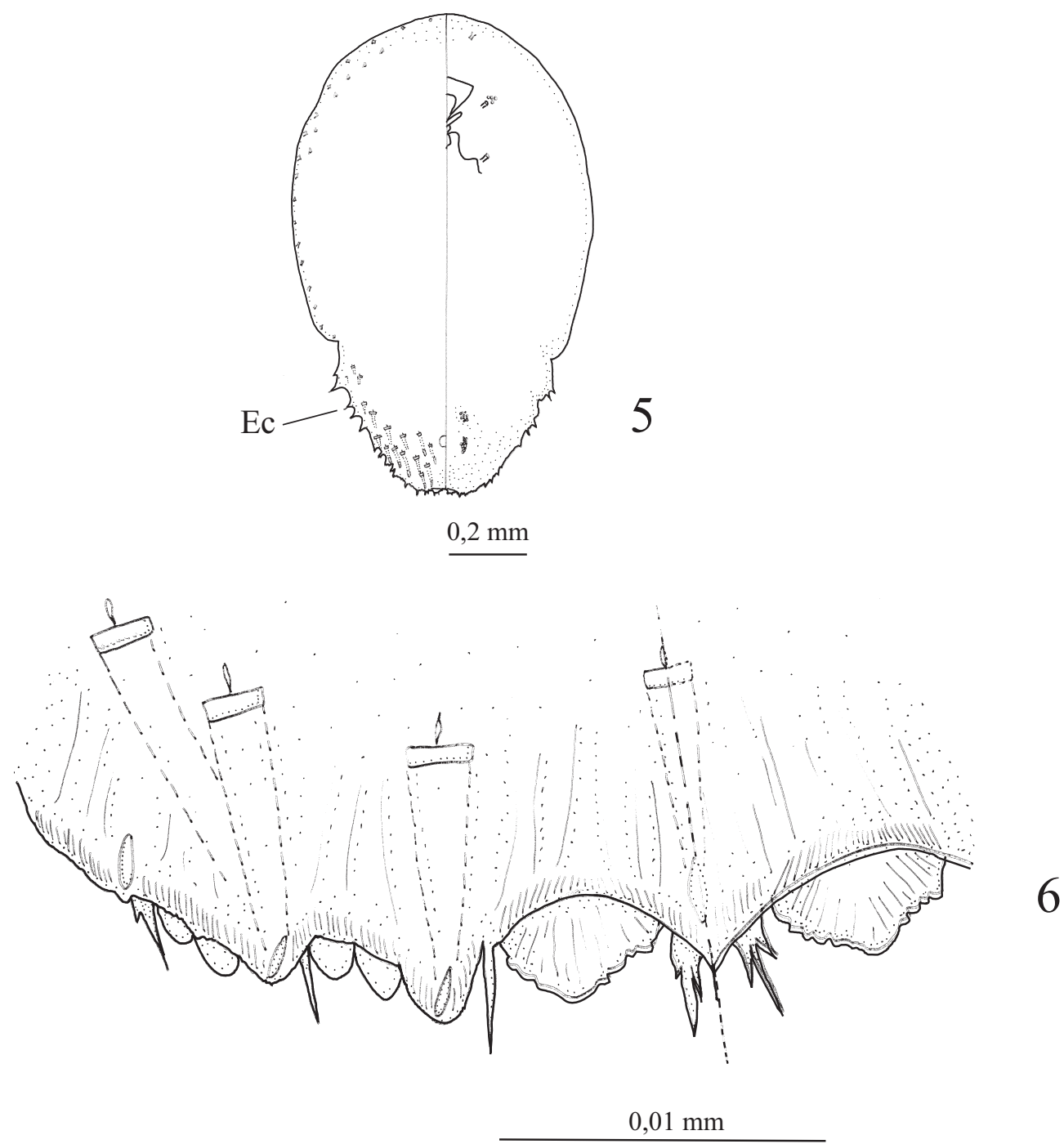

Figuras 5, 6. Desenho esquemático de Diaspidistis tucumanensis sp. nov.: 5, corpo inteiro da fêmea adulta (à esquerda estruturas dorsais, à direita ventrais); 6, margem do pigídio (Ec, espinho curto). 
fortemente esclerotizada na base, porém sem um prolongamento esclerotizado até quase a altura do ânus.

Etimologia. O nome específico é um substantivo em aposição à localidade-tipo.

Chave para identificação das espécies de Diaspidistis, baseada nos caracteres de fêmeas adultas.

1. Lóbulos medianos espatulados, com um ou dois entalhes em cada lado

1'. Lóbulos medianos com margens serrilhadas ........... 5

2. Margem pigidial anterior ao terceiro par de lóbulos sem processos semelhantes a lóbulos

D. petasata (Ferris, 1942)

2'. Margem pigidial anterior ao terceiro par de lóbulos com processos semelhantes a lóbulos

3. Margem anterior do corpo arredondada

D. gomescostai (Lepage \& Giannotti, 1946)

3'. Margem anterior do corpo sempre com um entalhe mediano

4. Tubérculos antenais com duas setas D. fonsecai sp. nov.

4'. Tubérculos antenais com três ou quatro setas D. multilobis Hempel, 1900

5. Espiráculos anteriores com oito ou mais glândulas periespiraculares, margem do abdômen, anterior aos ao terceiro par de lóbulos com cerca de 10 processos semelhantes a lóbulos

D. squamosa Hempel, 1937

5'. Espiráculos anteriores menos de oito glândulas periespiráculares, margem do abdômen, anterior aos L3, lisa, apenas com espinhos glandulares ....... 6

6. Corpo fortemente esclerotizado

D. tucumanensis sp. nov.

6'. Corpo membranoso

7

7. Sem lóbulos abdominais pré-pigidiais, prolongamentos esclerotizados da base dos lóbulos medianos até altura do ânus ........ D. memorabilis (Ferris, 1941)

7'. Com lobos abdominais e sem prolongamentos esclerotizados nos lóbulos medianos ...... D. multipunctata (Lepage \& Giannotti, 1946)

Agradecimentos. Aos curadores e responsáveis pelas coleções: Dr. S. Ide (IBSP); C. Camponer (MZSP); Dr. S. L. Heydon (UCDC) pelo empréstimo de material e à Fundação de Pesquisa Agropecuária (FEPAGRO) pela disponibilização do laboratório e Museu de Entomologia (MRGC) para realização do trabalho.

\section{REFERÊNCIAS BIBLIOGRÁFICAS}

Ben-Dov, Y.; Miller, D. R. \& Gibson, G. A. P. 2008. ScaleNet: Classification. Disponível em: <http:// www.sel.barc.usda.gov/scalenet/scalenet.htm>. Acesso em: 16.04.2008

Borchsenius, N. S. 1966. A catalogue of the armoured scale insects (Diaspidoidea) of the world. Nauka, Moscow \& Leningrad. 449p.

Claps, L. E.; Wolff, V. R. S. \& GonzÁlez, R. H. 2001. Catálogo de las especies de Diaspididae (Hemiptera: Coccoidea) nativas de Argentina, Brasil y Chile. Insecta Mundi 13(3/4):239-256.

Corseuil, E. \& Silva, T. L. 1971. A tribo Diaspidini no Rio Grande do Sul (Hom., Diaspididae). Arquivos do Museu Nacional do Rio de Janeiro 54:109-112.

Costa, R. G. \& Redaelli, D. C. 1949. Cochonilhas ou coccídeas do Rio Grande do Sul. Porto Alegre, Secção de Informações e Publicidade Agrícola. 107p

Fernald, M. E. 1903. A catalogue of the Coccidae of the world Bulletin of the Hatch Experiment Station of the Massachusetts Agricultural College 88:1-360.

FERRIS, G. F. 1936. Contributions to the knowledge of the Coccoidea (Homoptera). II. Microentomology 1:17-92.

1937. Contributions to the knowledge of the Coccoidea (Homoptera). IV. Microentomology 2:1-45.

1941. Atlas of the scale insects of North America. Series 3. Palo Alto, Stanford University. 230p.

1942. Atlas of the scale insects of North America Series 4. Palo Alto, Stanford University. 243p.

FonseCA, J. P. DA 1969. Contribuição ao conhecimento dos coccídeos do Brasil (Homoptera-Coccoidea). Arquivos do Instituto Biológico 36(1):9-40.

Hempel, A. 1900. As coccidas Brasileiras. Revista do Museu Paulista 4:365-537.

1937. Novas espécies de coccídeos (Homoptera) do Brasil. Arquivos do Instituto Biologico 8:5-36.

Lepage, H. S. 1938. Catálogo dos coccídeos do Brasil. Revista do Museu Paulista 23:327-491.

Lepage, H. S. \& Giannotti, O. 1946. Contribuição para o conhecimento dos coccídeos do Brasil (HomopteraCoccoidea). Arquivos do Instituto Biológico 17:37-46.

Lindinger, L. 1937. Verzeichnis der Schildlaus-Gattungen (Homoptera - Coccoidea). Entomologischen Jahrbuch 46:178-198

1943. Verzeichnis der Schildlaus-Gattungen, 1. Nachtrag (Homoptera: Coccoidea). Zeitschrift der Wiener Entomologischen Gesellschaft 28:217-224.

MacGillivray, A. D. 1921. The Coccidae. Urbana, Scarab. 502p. Miller, D. R. \& Gimpel, M. E. 2001. ScaleNet, Diaspidistis multilobis. Disponível <http://www.sel.barc.usda.gov/catalogs/ diaspidi/Diaspidistismultilobis.htm> Acesso em: 09.10.2009. 2006. ScaleNet. Disponível em: <http:// www.sel.barc.usda.gov/scalecgi/chklist.exe? Family $=$ Diaspididae $\&$ genus $=$ Pseudoparlatoria $>$ Acesso em: 07.10 .2008

Silva A. G. D .A.; Gonçalves, C. R.; Galvão, D. M.; Gonçalves, A. J. L.; Gomes, J.; Silva, M. N. \& Simoni, L. 1968. Quarto catálogo dos insetos que vivem nas plantas do Brasil, seus parasitos e predadores. Parte II. Insetos, hospedeiros e inimigos naturais. Rio de Janeiro, Ministério da Agricultura. v. 1. 622p

Vernalha, M. M. 1953. Coccídeos da coleção I.B.P.T. Arquivos de Biologia e Tecnologia 8(12):162-197.

Williams, D. J. 1985. Some South American scale insects (Homoptera: Coccoidea) on Nothofagus. Journal of Natural History 19: 249-258.

WolfF, V. R. S. 2001. Dez espécies novas de Pseudoparlatoria Cockerell, 1892 (Hemiptera: Coccoidea: Diaspididae). Arquivos do Instituto Biológico 68(2):67-76.

2008. Revisão de Pseudoparlatoria (Hemiptera, Diaspididae). Iheringia, Série Zoologia, 98(3):1-17. 